\title{
DESENVOLVIMENTO ORGANIZACIONAL COM BASE EM ESTRATÉGIAS DE DIVERSIFICAÇÃO
}

\author{
Organizational development \\ based on diversification strategies
}

Envio 21.07.08 / Aceite 01.08.08

\author{
Cristiane Froehlich ${ }^{1}$ \\ Claudia Cristina Bitencourt ${ }^{2}$
}

\section{Resumo}

Este artigo busca analisar o crescimento de uma organização pertencente à indústria calçadista do RS, que, em 2008, completa 63 anos. Trata-se de uma pesquisa qualitativa, de natureza exploratória e descritiva, desenvolvida através do estudo de caso no Grupo Paquetá. Os dados foram coletados através de entrevistas semi-estruturadas e de análise documental. Os principais resultados encontrados revelam que a Paquetá, ao longo de sua trajetória, capturou oportunidades de expansão em áreas correlatas de atuação através da diversificação de linhas de produção e de segmentos de mercado, bem como mediante a integração vertical, mas também se expandiu em outros negócios não correlatos, como empreendimentos imobiliários e administração de cartões de crédito. Pode-se afirmar que a Paquetá soube aproveitar as oportunidades que surgiram diversificando seus negócios em um movimento não muito comum em relação às práticas organizacionais, entrando em mercados até então "desconhecidos" ou fora de sua área de especialidade.

Palavras-chave: Estratégias de Diversificação; Desenvolvimento Organizacional; Expansão de Negócios; Indústria Calçadista; Trajetória.

\footnotetext{
${ }^{1}$ Mestre em Administração pela Universidade do Vale do Rio dos Sinos (UNISINOS). Professora de cursos de extensão, graduação e pós-graduação no Centro Universitário FEEVALE. Endereço postal: Rua Joaquim Nabuco, 1.155, apto 702, Centro. Novo Hamburgo - CEP 93310-002 - RS. Telefone: (51)8164-5045. E-mail: cfroehlich@feevale.br

${ }^{2}$ Doutora em Administração pela Universidade Federal do Rio Grande do Sul (UFRGS). Pesquisadora e professora de cursos de extensão, graduação e pós-graduação da UNISINOS. Endereço postal: Av. Unisinos, 950. São Leopoldo - CEP 93022-000, RS. Unidade Acadêmica de Pesquisa e Pós-Graduação em Administração. E-mail: claudiacb@ unisinos.br
} 


\begin{abstract}
The present work analyses the growth of organization of a shoes industry on the State RS, which complete 68 years old this year. It is a qualitative research, with exploratory and descriptive characteristics, developed by the case study method in the Paquetá Group. The data were collected through semistructured interviews and documental analysis. The main results point out that the Paquetá Group has captured expansion opportunities into areas related of expertise through production lines and segments market diversification, as well the integration vertical, but also has expanded into not related bussines, such as real state office enterprise and credit cards administration.

The Paquetá knew used the emerged opportunities that business diversification, that situation it's not very common in the organizational practices of this industry, go in the market out expertise.
\end{abstract} Industry; Path.

Keywords: Diversification Strategies; Organizational Development; Expansion of Business; Shoes

\title{
1 Introdução
}

A literatura sobre estratégia ampliou-se de forma contínua e intensa ao longo dos anos, tornando-se, em muitos momentos, o tema central de debate nas escolas de administração e no mundo empresarial. Diferentes concepções foram desenvolvidas, com ênfases distintas e relacionamentos interdisciplinares. Essa amplitude e complexidade do termo impedem que se obtenha uma definição consensual, embora a revisão da literatura indique, além das contradições, algumas convergências conceituais.

A concordância se estabelece quando a estratégia diz respeito tanto à organização quanto ao ambiente; é complexa; afeta o bem-estar da organização; envolve questões tanto de conteúdo como de processo; não é puramente deliberada; existe em diferentes níveis organizacionais; envolve vários processos de pensamento; envolve a adequação da organização e seus processos internos ao seu ambiente de atuação e o posicionamento competitivo de uma empresa, dentre outros (PORTER, 1986; ANSOFF 1990; MINTZBERG, 2001; MEIRELLES, 2003).

Os estudos sobre estratégia, segundo Whittington (2004b), tradicionalmente, valorizam o desempenho e a vantagem competitiva da empresa. Porém, é importante analisar, principalmente, o processo que se utiliza para buscar os resultados, ou seja, como as ações estratégicas são estruturadas.

Este artigo tem como objetivo analisar o crescimento do Grupo Paquetá através de estratégias de diversificação dos seus negócios. Na construção desse ponto de vista, foram examinadas: as diferentes noções acerca da estratégia; o posicionamento inspirado em Porter (1986) e a questão da vantagem competitiva; os níveis estratégicos da organização - corporativo, de negócio e funcional; e, por fim, o crescimento da organização tendo como base a estratégia de diversificação. Na seqüência da fundamentação teórica, apresentam-se os procedimentos metodológicos utilizados seguidos dos principais resultados e conclusões.

\section{Noções acerca do termo estratégia}

Para Mintzberg (2001), estratégia é uma palavra definida de uma forma e utilizada de outra. O autor destaca que faz parte da natureza humana buscar um conceito único, mas 
afirma que a estratégia requer uma série de definições, que apresentam vários significados. O autor enfatiza que devido às mudanças no cenário, nem todas as estratégias formuladas são de fato implementadas. A possibilidade, cada vez maior, de novas oportunidades para a organização mostra a necessidade de implantar estratégias que ainda não tenham sido formuladas. Tais estratégias são denominadas de emergentes, e elas demandam flexibilidade e capacidade empreendedora da organização, e geram ajustes no processo de gestão estratégica competitiva.

Partindo deste conceito, o processo de formação de estratégias competitivas pode ser categorizado em: estratégias deliberadas, emergentes ou em uma combinação entre essas duas vertentes.

As estratégias deliberadas implicam um padrão de ação, admitem como pressuposto um comportamento pretendido tal como realizado, devido às intenções precisas, estabelecidas previamente pela liderança da organização e realizadas sem maiores interferências ambientais. Por outro lado, estratégias emergentes são aquelas realizadas sem ter uma intenção explícita, ou seja, é uma estratégia não planejada, em que a ação somente é percebida como estratégica pela empresa, na medida em que se desenvolve ou mesmo depois de ter acontecido. A diferença fundamental entre a estratégia deliberada e a emergente é que, enquanto a primeira enfatiza o planejamento, a direção e o controle, fazendo com que as intenções sejam realizadas, a última permite a noção de "aprendizado estratégico", isto é, as empresas desenvolvem-se à medida que o ambiente competitivo gera novos cenários de atuação (MINTZBERG, 2001).

Dessa forma, a organização não deve apenas ser estruturada e mobilizada para ser capaz de agir com presteza em seu ambiente complexo e em rápida mudança, mas deve também estar preparada para reconhecer, avaliar e adaptar-se às estratégias emergentes.

Portanto, podem ser encontrados diferentes modelos de formação e implementação de estratégias que são importantes para uma organização que enfrenta desafios complexos. Para tratar desse assunto, a base da discussão apresentada centraliza-se em Porter (1986), considerado um dos autores mais referenciados neste campo.

\section{$3 \mathrm{O}$ posicionamento inspirado em Porter e a vantagem competitiva}

Andrews (2001) afirma que a definição da estratégia a ser adotada deve desenvolverse com base no ambiente externo e interno. A análise do ambiente externo revela ameaças e oportunidades que, associadas aos recursos e às capacidades internas da empresa, servem como guia para o estabelecimento do posicionamento estratégico.

Para o entendimento do ambiente externo, tem sido utilizado, de forma ampla, o modelo de análise da indústria, proposto por Porter na década de 1980. O autor baseia-se na avaliação de cinco forças competitivas: ameaça de novos entrantes, poder de negociação dos fornecedores, poder de negociação dos clientes, ameaça de produtos substitutos e competição intra-indústria. Em síntese, o entendimento dessas forças possibilita avaliar a perspectiva de rentabilidade de um setor e, ainda, diversas outras dimensões ambientais a serem consideradas na estratégia da empresa.

Desse modo, o posicionamento competitivo é que determina se uma empresa terá rentabilidade abaixo ou acima da média desta indústria. Repercute na vantagem competitiva da empresa, ou seja, uma empresa atinge uma vantagem competitiva se obtiver taxas maiores de rentabilidade do que as empresas rivais. As definições quanto ao escopo competitivo e ao 
tipo de vantagem competitiva a ser seguida constituem-se nos elementos centrais da estratégia (FAIRBANKS e LINDSAY, 2000; HEXSEL e PAIVA, 2006; BESANKO, 2006).

Por isso, Porter (1986) afirma que a escolha do escopo é importante, pois indica a decisão sobre a prioridade quanto a investimentos em produtos e mercados. Para definir o escopo competitivo, uma empresa deve avaliar a atratividade potencial dos diversos mercados. A atratividade de um mercado decorre de seu tamanho, da taxa de crescimento, intensidade competitiva presente e da capacidade de a empresa desenvolver uma estratégia competitiva sustentável e adequada.

O escopo classifica-se em amplo ou restrito A definição do tipo de escopo está atrelada aos critérios de escolha dos segmentos de atuação e aos benefícios e às dificuldades apresentadas por cada um desses escopos (PORTER, 1986). Um escopo amplo permite explorar as relações entre os produtos que servem diferentes segmentos. Já um escopo restrito permite uma melhor adequação da oferta a um segmento de mercado, a fim de obter menores custos ou maior diferenciação.

Porter (1986) defende que apenas tomar decisões sobre a posição não é o suficiente. Afinal, os concorrentes podem reposicionar-se na direção dessa mesma posição ou incluir os benefícios desse posicionamento em suas posições atuais por meio da inclusão de produtos, serviços ou tecnologias em suas atividades atuais. Dessa maneira, uma efetiva estratégia sustentará a vantagem competitiva apenas se evitar esse tipo de manobra.

Sobre a definição do formato da vantagem competitiva, Porter (1986) afirma que deve ser estabelecida prioridade quanto à diferenciação e ao custo. A combinação desses dois tipos de vantagem competitiva com o escopo de atividades leva a três estratégias genéricas para alcançar um desempenho acima da média do setor: liderança de custo, diferenciação e enfoque, que se subdivide em enfoque no custo e enfoque na diferenciação (PORTER, 1986).

Sendo assim, a análise da vantagem competitiva está centrada no conceito de atividades. Todas as diferenças entre as empresas, seja em preços seja em custos, estão localizadas, em última análise, no amplo número de atividades requeridas para criar, produzir, vender e distribuir produtos ou serviços (HEXSEL e HENKIN, 2002).

Uma implicação dessa visão é que um posicionamento estratégico, para ser efetivo, deve contar com um horizonte de tempo relativamente longo, pois as atividades devem ser constantemente reforçadas, assim como os seus alinhamentos. Pensando desse modo, percebese o porquê da dificuldade de manobras de reposicionamento.

A seguir, apresentam-se os níveis estratégicos da organização, que se inserem na óptica interna da organização. Esses níveis podem ter estratégias deliberadas e emergentes de forma simultânea ou não. A decisão implica compreender o contexto onde a empresa está inserida e a capacidade de percepção dos dirigentes, gestores em relação ao ambiente.

\section{Os níveis estratégicos da organização: corporativo, de negócio e funcional}

As estratégias deliberadas e/ou emergentes podem ser classificadas em função do nível interno da estrutura organizacional em que são tomadas as decisões. Essa classificação pontua a estratégia corporativa; a estratégia da unidade de negócios; as estratégias funcionais (PIRES, 1995). A estratégia corporativa (do grupo empresarial) refere-se ao ambiente em que o grupo empresarial atua, sendo fundamental na sua definição o reconhecimento de suas forças e fraquezas. Na formulação da estratégia corporativa, é importante que os gestores estejam cientes dos fatores ambientais que poderão, de alguma forma, afetar o grupo, tais como tecnologia, 
ecologia, aspectos econômicos, setor em que a empresa atua, sociedade e aspectos políticos (PAIVA, CARVALHO e FENSTERSEIFER, 2004).

Um grupo empresarial, normalmente, busca uma sinergia entre todas as suas unidades estratégicas de negócios. Conforme Porter (1986), a estratégia corporativa diz respeito a duas grandes questões: em que negócios a corporação deveria atuar e como a corporação deveria administrar o conjunto de negócios. Sendo assim, a estratégia corporativa é que faz a corporação ser mais que a simples soma de suas unidades de negócios. Uma das vantagens desse nível estratégico refere-se ao estabelecimento de um plano de alocação de recursos e trocas de experiências.

É importante destacar que a estruturação em Unidades Estratégicas de Negócios (UENs) é descentralizada, dispondo a cada negócio uma autonomia que tenta reproduzir, em grande parte, o todo organizacional. A organização torna-se um conjunto de "pequenas" organizações administradas com o máximo de interdependência. A conexão entre as partes faz-se por um amplo sistema de comunicação e por uma filosofia organizacional compartilhada. Esse tipo de estrutura organizacional facilita a coordenação estratégica, uma vez que cada unidade é projetada com menor hierarquia e maior autonomia e com um equilíbrio de poder baseado num processo decisório participativo (LOBATO et al., 2005).

A estratégia funcional deve dar suporte à estratégia da empresa e apoiar as outras estratégias funcionais para a consecução dos objetivos empresariais. Exemplos típicos de estratégias funcionais são advindos das áreas de: produção, marketing, finanças, pesquisa e desenvolvimento e recursos humanos. Independente do nível estratégico observado, o objetivo da organização é o seu crescimento. Essa discussão é proposta a seguir.

\section{Crescimento da organização mediante a estratégia de diversificação}

O crescimento de uma organização ocorre quando ela desenvolve gradualmente suas atividades, ampliando suas capacitações. A organização aumenta sua participação no mercado em que atua e procura novos mercados, sendo que cada empresa tem seu padrão próprio de encarar o crescimento. Enquanto algumas adotam uma posição mais conservadora de crescimento, outras adotam uma postura mais agressiva, tornando-se uma necessidade de sobrevivência.

Conforme Galbraith (2001), a primeira mudança estratégica que uma organização faz é integrar-se verticalmente dentro de seu setor, para garantir as fontes de suprimentos e volume, para investimentos de capital, e tornar-se um cliente para dar feedback para novos produtos. Uma das primeiras manobras de diversificação que uma empresa verticalmente integrada faz é vender subprodutos ao longo da cadeia do setor.

Os principais motivos que levam uma organização à diversificação, pontuados pela literatura, podem variar tanto entre ramo de atividades quanto intra-ramo. No mercado, a empresa atua em um ambiente de incertezas. Diante dessa realidade, o grau de aversão ao risco que apresenta é fator a permear suas decisões estratégicas, pois colocar todos os seus recursos em uma única linha de produtos pode pô-la em risco diante de um quadro de desaceleração da demanda. A diversificação de atividades, portanto, preserva a empresa em situações como essas (GEORGE e JOLL, 1983).

A diversificação pode ocorrer, igualmente, para explorar novas oportunidades de mercado. Produtos sujeitos aos ditames da moda, como no caso dos calçados, em que se diversificam estilos, materiais empregados e finalidades de consumo, podem trilhar novos 
caminhos de expansão. Um exemplo ilustrativo é a difusão de calçados esportivos em decorrência de mudanças no padrão de vida das pessoas, em que se valoriza a prática de esportes, caminhadas ao ar livre, entre outros.

Penrose (1959) vê que o limite do mercado não é restrição absoluta ao crescimento da empresa, desde que ela saiba fazer uso dos serviços e dos recursos que tem. Isso pode ocorrer porque a empresa, ao longo do tempo, assimilou um conjunto de rotinas e conhecimentos que condicionam o seu comportamento futuro. Conforme Dosi et al. (1992), há uma coerência empresarial (corporate coherence) em termos de diversificação, pois ela tende a incorporar novas linhas de produtos em áreas relacionadas àquela que já vinha atuando.

Esse tipo de configuração possui quatro vantagens econômicas. Primeiro, encoraja a alocação eficiente de capital, podendo a organização escolher em que colocar seu dinheiro e concentrar-se em seus melhores mercados. Segundo, ao abrir as oportunidades para administrar negócios diferentes, a configuração diversificada oportuniza o desenvolvimento de competências gerências. Terceiro, essa configuração dissemina seus riscos por mercados diferentes. Quarto, a configuração diversificada é estrategicamente responsiva, pois pode adquirir novos negócios e eliminar os antigos improdutivos (MINTZBERG, 2001).

Para Chandler (1962), é o grau de adequação entre estratégia de crescimento e estrutura organizacional que irá orientar o "sucesso" das firmas no mercado. Isso quer dizer que os caminhos de expansão distintos requerem formas organizacionais particulares que lhes dêem efetividade. Então, a empresa organizada sob a forma unitária foi efetiva enquanto produzia uma única linha de produto. No entanto, quando a estratégia se modificou em direção a linhas de produtos diversificados, essa estrutura organizacional perdeu a funcionalidade, sendo substituída pela forma multidivisional.

Em síntese, uma empresa é diversificada se produz para vários mercados e pode diversificar-se de várias formas, como por meio de crescimento interno, de formação de alianças estratégicas, de joint ventures, de fusões ou de aquisições.

Portanto, a criação de estratégias tem de ser um processo contínuo, em que estratégias emergentes, juntamente com as estratégias deliberadas, possuem um papel crucial. Mas, para tirar-se proveito delas, os gestores terão de dominar o uso de estruturas, processos e técnicas que permitem transformar estratégias competitivas em comportamento estratégico eficaz (MARIOTTO, 2003), podendo, dessa forma, mobilizar efetivamente as competências necessárias.

\section{Procedimentos metodológicos}

O presente artigo classifica-se como uma pesquisa de natureza qualitativa, pois analisa um caso concreto nas suas particularidades temporal e local, partindo das expressões das pessoas e das suas atividades em seus contextos locais.

A pesquisa desenvolve-se por meio de uma investigação exploratória e descritiva, pois investiga um fenômeno com o propósito de melhor compreendê-lo, podendo lançar alguns novos insights e descrever elementos relacionados a essa situação. Importante destacar que o estudo descritivo tem como objetivo conhecer e interpretar a realidade sem nela interferir para interpretá-la (CHURCHILL, 1987).

Para analisar o objeto, o estudo utiliza um dos métodos da pesquisa qualitativa: o estudo de caso único, indicado para a análise profunda, quando o pesquisador visa a examinar determinado ambiente de modo detalhado, um sujeito ou uma situação particular (LEE, 1998; MARSHALL e ROSSMAN, 1999; FLICK, 2004). 
A coleta de dados foi realizada por meio de entrevista semi-estruturada com 22 diretores e gestores da empresa, conforme mostra o Quadro 1. Como fonte de dados secundários, citamse as pesquisas bibliográficas e documentais.

\begin{tabular}{|c|c|c|c|}
\hline N. ${ }^{\circ}$ & Cargo & $\begin{array}{l}\text { Tempo de } \\
\text { Atuação na } \\
\text { Empresa }\end{array}$ & Grau de Instrução \\
\hline 1 & Sócio-Fundador & 24 anos & Ensino fundamental incompleto \\
\hline 2 & Sócio-Fundador do varejo & 26 anos & Ensino médio completo \\
\hline 3 & Diretor Presidente & 35 anos & $\begin{array}{l}\text { Graduação incompleta em } \\
\text { administração de empresas e economia }\end{array}$ \\
\hline 4 & Diretor de Infra-Estrutura & 22 anos & $\begin{array}{l}\text { Graduado em arquitetura e engenharia } \\
\text { de segurança de trabalho }\end{array}$ \\
\hline 5 & Diretor Industrial da manufatura & 16 anos & Graduado em gestão da produção \\
\hline 6 & Diretora de Marcas & 20 anos & $\begin{array}{l}\text { Graduação incompleta; cursos de } \\
\text { moda, estilo e modelagem }\end{array}$ \\
\hline 7 & $\begin{array}{l}\text { Diretor Comercial do varejo na região } \\
\text { nordeste }\end{array}$ & 21 anos & Graduação incompleta \\
\hline 8 & $\begin{array}{l}\text { Diretor Comercial do varejo na região sul } \\
\text { e sudeste }\end{array}$ & 15 anos & Graduação em engenharia \\
\hline 9 & Diretor Administrativo das fazendas & 15 anos & Graduação incompleta \\
\hline 10 & Gestor de Negócio - Couros & 5 anos & $\begin{array}{l}\text { Graduado em administração de } \\
\text { empresas }\end{array}$ \\
\hline 11 & Gerente de Tecnologia & 17 anos & $\begin{array}{l}\text { Graduado em engenharia mecânica e } \\
\text { especialista em engenharia }\end{array}$ \\
\hline 12 & Gerente Técnico de Laboratório & 32 anos & Ensino fundamental incompleto \\
\hline 13 & Gestor de Negócio - Esportivo & 20 anos & $\begin{array}{l}\text { Graduação em administração de } \\
\text { empresas }\end{array}$ \\
\hline 14 & Gestor de Negócio - Exportação & 2 anos & $\begin{array}{l}\text { Graduado em gestão da produção, e } \\
\text { em andamento graduação em } \\
\text { administração de empresas }\end{array}$ \\
\hline 15 & Gestor de Negócio - Dumond & 1 ano & $\begin{array}{l}\text { Graduado em publicidade e } \\
\text { propaganda }\end{array}$ \\
\hline 16 & Gerente de produção da Dumond & 5 anos & Mestre em Administração \\
\hline 17 & Gerente de Recursos Humanos & 39 anos & $\begin{array}{l}\text { Curso técnico de contabilidade e } \\
\text { segurança no trabalho, graduação } \\
\text { incompleta em administração }\end{array}$ \\
\hline 18 & $\begin{array}{l}\text { Gerente Comercial e Desenvolvimento da } \\
\text { manufatura de exportação }\end{array}$ & 23 anos & $\begin{array}{l}\text { Graduação em gestão da produção em } \\
\text { andamento }\end{array}$ \\
\hline 19 & $\begin{array}{l}\text { Gerente Comercial da manufatura de } \\
\text { exportação direto para cliente (sem } \\
\text { intermédio de trading) }\end{array}$ & 12 anos & Graduação em gestão da produção \\
\hline 20 & $\begin{array}{l}\text { Gerente de Formação de Preço de Venda } \\
\text { da manufatura }\end{array}$ & 10 anos & $\begin{array}{l}\text { Graduação em gestão da produção em } \\
\text { andamento }\end{array}$ \\
\hline 21 & Gerente de Desenvolvimento Humano & 17 anos & $\begin{array}{l}\text { Graduado em administração de } \\
\text { recursos humanos e especialista em } \\
\text { gestão empresarial }\end{array}$ \\
\hline 22 & Técnico de calçados & 45 anos & Ensino fundamental incompleto \\
\hline
\end{tabular}

Fonte: Elaborado pelas autoras, 2007.

Quadro 1 - Número de pessoas entrevistadas e seus respectivos cargos, tempo de atuação na empresa e grau de instrução do Grupo Paquetá e da Abicalçados.

Rev. Adm. UFSM, Santa Maria, v. 1, n. 2, p. 241-262, mai./ago. 2008 
Os dados coletados foram analisados por meio da análise de conteúdo qualitativa (FLICK, 2004). Para isso, foram criadas, a priori, com base no referencial teórico, a categoria "estratégias organizacionais", composta por quatro subcategorias: a) estratégias deliberadas e emergentes; b) posicionamento e vantagem competitiva; c) os níveis estratégicos: corporativo, de negócios e funcional e; d) crescimento da organização através de estratégias de diversificação.

Neste estudo, não se pretende esgotar o assunto, mas levantar e aprofundar reflexões que tratem do desenvolvimento organizacional através de estratégias de diversificação.

\section{A empresa Paquetá}

A Paquetá é um Grupo da indústria calçadista, que, em 2008, completa 63 anos. Possui negócios diversificados, atuando nos segmentos de manufatura de calçados do tipo feminino e esportivo; varejo de calçados e acessórios; curtume de acabamento em couros; agropecuária; empreendimentos mobiliários e administração de cartões de crédito.

O Grupo conta com aproximadamente 18.000 mil funcionários, deste total, cerca de 13.450 mil fazem parte do negócio de manufatura de calçados, em torno de 4.000 mil integram o negócio do varejo; 300 funcionários compõem o negócio agropecuário e 250 funcionários estão distribuídos entre os negócios de empreendimentos imobiliários e administração de cartão de créditos.

Ao longo do tempo, o Grupo foi se desenvolvendo organizacionalmente. Esse processo pode ser mais bem visualizado na Figura 1, que apresenta a linha do tempo por décadas do Grupo Paquetá: 


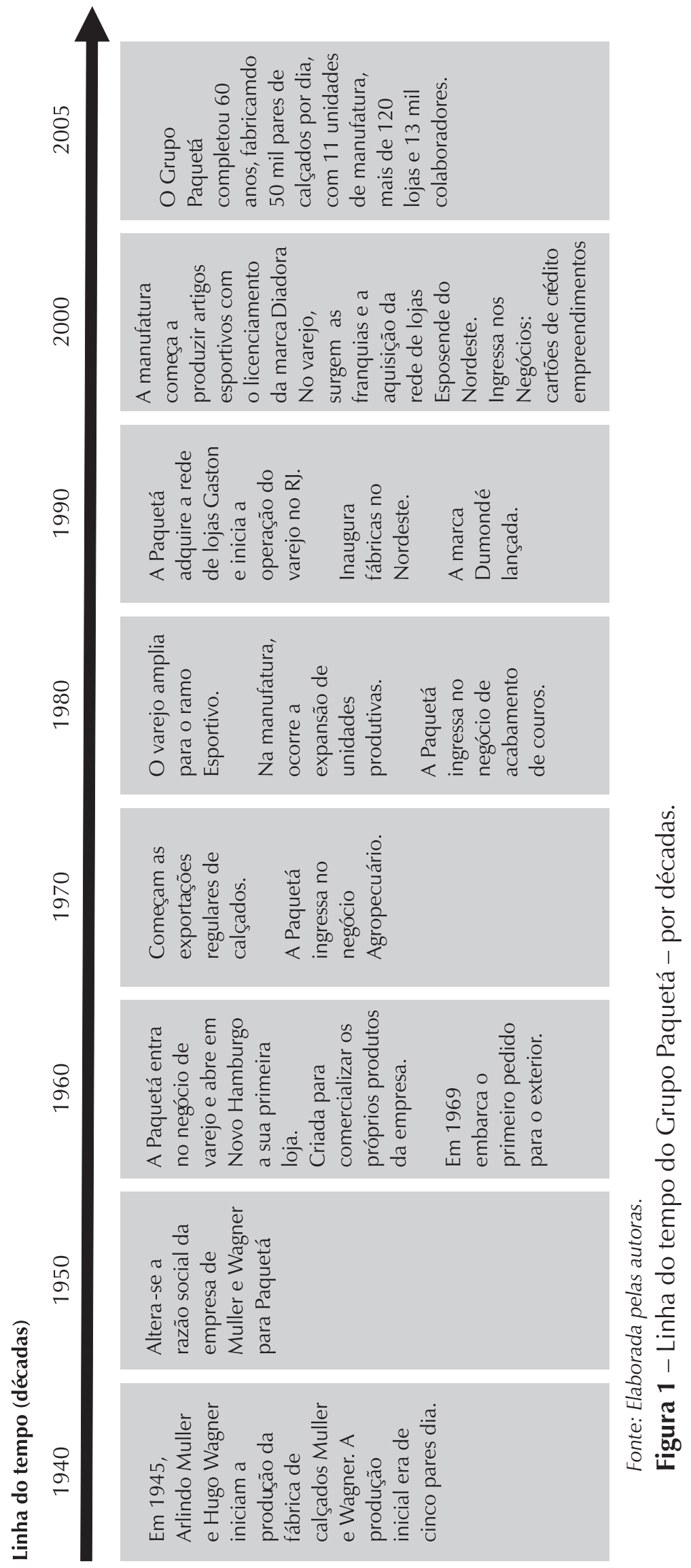

Rev. Adm. UFSM, Santa Maria, v. 1, n. 2, p. 241-262, mai./ago. 2008 - 249 - 


\subsection{O crescimento da Paquetá através de estratégias de diversificação}

A Paquetá, ao longo de sua trajetória, adotou, como estratégia de crescimento, a diversificação em negócios, em produtos e em mercados. Essa estratégia preserva a empresa em situações de desaceleração da demanda e de seu produto (GEORGE e JOLL, 1983), e foi pensando assim que a Paquetá adotou a estratégia de diversificação.

Quanto ao crescimento do Grupo Paquetá, percebe-se que dos anos 1945 a 1955 o crescimento foi lento, depois de 1955 a 1965 houve um crescimento um pouco maior, mas o grande boom foi com o início das exportações de marca de terceiros depois da década de 1970. A diversificação dos negócios foi uma opção estratégica, porque buscavam alternativas de ganhos caso houvesse uma mudança brusca em algum mercado.

Geralmente uma das primeiras manobras de diversificação que uma empresa verticalmente integrada faz é vender subprodutos ao longo da cadeia do setor, e isso se aplica às estratégias adotadas pelo Grupo (GALBRAITH, 2001).

Quanto à diversificação na Paquetá, ela iniciou suas atividades no negócio de manufatura em 1945, fabricando produtos masculinos até 1948 e, em 1949, começaram a produzir o produto feminino. Essa mudança ocorreu porque as vendas de sapatos de couro para mulheres eram em maior volume do que os calçados para homens. Isso permitia a ocupação plena dos recursos e a perspectiva de expansão. Já em 1958, além de calçados femininos, começaram a produzir também calçados infantis, cuja fabricação durou aproximadamente nove anos. Mas, como no final da década de 1960 ingressaram no mercado de exportação, o volume de pedidos de calçados femininos aumentou significativamente e foi necessário parar com a produção de calçados infantis. Além de produzir sapatos femininos em couro para o mercado de exportação, em 1995, adotaram como estratégia a produção de calçados femininos de sintético para atender aos consumidores das classes " $\mathrm{C}$ " e " $\mathrm{D}$ " e também para reduzir os custos internos. Porém, essa estratégia não trouxe resultados satisfatórios e, em 2000, decidiram encerrar a produção dessa linha de calçados.

Uma estratégia para contornar a limitação de mercado foi ingressar no segmento de calçados esportivos, em 1996, por meio do licenciamento da marca estrangeira Diadora e, em 2002, começou a produzir a marca Adidas. Em 1995, retomou as atividades do mercado interno e investiu na marca própria Dumond que, desde 2001, atua no mercado internacional. O que levou a retomada ao mercado interno, em 1995, foi a percepção de que a China começou a entrar no mercado e pensaram nas possíveis dificuldades que surgiriam. Além disso, também influenciou esta decisão a instabilidade da moeda.

O Quadro 2 apresenta a diversificação de produtos e de mercados do negócio de manufatura. 


\begin{tabular}{|l|c|c|l|}
\hline Produtos: linhas de calçados & $\begin{array}{c}\text { Início da } \\
\text { produção }\end{array}$ & $\begin{array}{c}\text { Ano de } \\
\text { encerramento }\end{array}$ & Mercado de destino \\
\hline Masculino & 1945 & 1948 & Interno \\
\hline Feminino com cabedal de couro & 1949 & permanece & Externo \\
\hline Infantil & 1958 & 1969 & Interno \\
\hline Feminino com cabedal sintético & 1995 & 2000 & Interno \\
\hline Esportivo & 1996 & permanece & Interno e externo \\
\hline $\begin{array}{l}\text { Feminino com cabedal em couro, } \\
\text { em tecidos e outros materiais } \\
\text { (Dumond) }\end{array}$ & 1995 & permanece & Interno e externo \\
\hline
\end{tabular}

Fonte: Elaborado pelas autoras, com base em fontes do Grupo Paquetá.

Quadro 2 - Composição das linhas de produção de calçados da Paquetá: 19452005.

Em 1964, os dirigentes perceberam o desenvolvimento do Vale dos Sinos, à margem da BR-116 e que o público de Porto Alegre vinha para Novo Hamburgo comprar sapatos na "cidade do calçado". Com isso, inaugurou-se a primeira loja em Novo Hamburgo. Com o passar dos anos, o varejo tornou-se um negócio próprio, com administração independente da manufatura, e, hoje, constitui-se uma das maiores redes de lojas de calçados do Brasil. A visão da Paquetá é de se tornar uma rede de varejo de calçados cada vez maior e mais forte por meio da abertura de novas lojas e da aquisição de novas redes no Estado e fora dele.

Em 1978, a empresa ingressou no negócio agropecuário por meio da compra de fazendas no Mato Grosso do Sul. Na década de 1980, entrou no negócio de acabamento de couro. Na década de 2000, ingressou no ramo de empreendimentos imobiliários e na administração de cartões de créditos.

Vê-se que o Grupo Paquetá soube fazer uso dos seus serviços e dos seus recursos internos para crescer (PENROSE, 1959). Portanto, a diversificação consiste numa oportunidade desde que a empresa saiba mobilizar seus recursos. Até o final da década de 1990, houve uma coerência nas diversificações promovidas pelo Grupo (corporate coherence), pois incorporou novas linhas de produtos em áreas relacionadas àquela que já vinha atuando (DOSI et al., 1992). Mas, a partir da década de 2000, diversificou em negócios que não estão diretamente relacionados a sua área de atuação, como os empreendimentos imobiliários e a administração de cartões de crédito. Isso pode ser explicado por Penrose (1959), que afirma "desde que a organização saiba fazer uso dos serviços e dos recursos que têm", conforme citado anteriormente. Para complementar essa idéia, vale destacar que essa diversificação pode ocorrer para explorar novas oportunidades de mercado, a fim de gerar resultados para organização.

\subsection{Estratégias organizacionais da Paquetá}

Para o Grupo manter-se competitivo durante a sua trajetória, teve de desenvolver, muitas vezes, estratégias emergentes e adequar seus objetivos visando à competitividade e à busca da consolidação de diferenciais competitivos.

A implementação das estratégias geralmente envolve mudanças promovidas principalmente pelo ambiente externo, no caso específico, a necessidade do cliente buscar um 
produto diferenciado, de melhor qualidade. Nesse contexto, as estratégias podem assumir um caráter deliberado ou emergente.

Em síntese, as principais mudanças ocorridas na Paquetá foram: (a) na década de 1980, deixaram de atender o mercado interno e voltaram-se especialmente para atender o mercado americano; (b) na década de 1990, por volta de 1995, o único agente da Paquetá levou os seus pedidos para serem produzidos na China; (c) em 1995, investimento na marca própria Dumond; (d) em 1997, abertura da primeira unidade de manufatura na região nordeste. A estratégia tomada quanto à abertura de unidades de manufatura no Ceará e na Bahia ocorreu para amenizar principalmente a instabilidade do câmbio. Para que os clientes não cogitassem a possibilidade de que os produtos produzidos no Nordeste teriam qualidade inferior aos produtos do Sul, o Grupo decidiu certificar as unidades situadas no Nordeste com a ISO 9001.

O Grupo hoje atua por meio da estratégia de diferenciação, em que o foco do trabalho não é o preço, mas sim a qualidade do produto. Abandonar um diferencial que por tanto tempo foi buscado pelo setor calçadista implica uma mudança de mentalidade e uma predisposição a correr riscos. É uma nova forma de se pensar a estratégia da empresa. Nesse sentido, Porter (1986) afirma que, por meio de uma estratégia de diferenciação, a empresa busca agregar valor em aspectos considerados importantes pelo cliente.

Para consolidar essa nova estratégia de atuação, o Grupo, atualmente, está encontrando algumas dificuldades em relação à compra de materiais de fornecedores locais e nacionais para atender aos clientes com produtos de valor agregado. Entre essas dificuldades destaca-se a falta de capacitação e especialização de fornecedores no desenvolvimento de cabedais para tênis; a caixa individual da marca Hugo Boss teve que ser importada da China, pois fornecedores locais e nacionais não conseguiram desenvolver a caixa dentro dos padrões exigidos pela marca. Portanto, os fornecedores também precisam migrar e adotar estratégias de diferenciação para ingressar no mercado de maior valor agregado e com qualidade, a fim de evitar a importação de insumos e componentes de outros países.

Como parte do processo de reestruturação corporativa, são definidos: a Visão de Futuro, Missão, Valores e Política da Qualidade do Grupo Paquetá, conforme segue:

- visão de futuro: ter uma marca com posicionamento no mundo até 2010;

- missão: proporcionar conforto e prazer às pessoas que querem andar na moda, sendo uma empresa forte, ética e dinâmica, com resultados para seus sócios, funcionários e comunidade;

- valores: ética, trabalho, dinamismo, honestidade, preocupação com a comunidade, humildade nas relações pessoais;

- política de qualidade: desenvolver, produzir e comercializar produtos de vestuário, conforme as necessidades do cliente, baseado na melhoria contínua, na qualificação e satisfação das pessoas, em condições adequadas de trabalho com competitividade e lucratividade.

A partir dessas definições, o Grupo começou a desenvolver um Planejamento Estratégico (PE) formalizado e estruturado, cuja implantação iniciou em 2004. Para isso, contratou uma empresa de consultoria para apoio na elaboração do PE. Apresentam-se, a seguir, algumas definições de como está estruturado o planejamento estratégico do Grupo:

- como o Grupo Paquetá possui atuações distintas no mercado, o PE é segmentado por negócio e, dentro de cada unidade de negócio, existe o plano de expansão e marketing de cada mercado. O direcionamento estratégico da empresa está fundamentado em informações de mercado, concorrência, histórico do desempenho (tanto financeiro como performance em 
relação aos objetivos em curso). O horizonte de tempo considerado para o PE é de cinco anos e, a cada ano, é feita a revisão do conteúdo e das metas;

- a concepção do PE inicia-se pelo corporativo, usualmente em setembro de cada ano, no qual participam a presidência e a diretoria para definir as premissas estratégicas, um cenário corporativo e uma meta financeira de retorno para os acionistas sobre o capital aplicado. Este conteúdo passa a ser a base das discussões para a revisão do planejamento existente e é transmitido para as unidades a partir de outubro de cada ano;

- nas unidades, participam os gestores das unidades de negócios e seus gerentes, junto com os representantes da controladoria financeira e estratégica do grupo, que tem até a metade de dezembro como prazo para o desenvolvimento do planejamento das unidades. $\mathrm{O}$ ciclo fecha-se com a validação do PE pela diretoria corporativa, formalizando o compromisso de desempenho para o ano seguinte;

- as estratégias, então, são comunicadas através da construção do mapa estratégico, realizado de forma participativa com os gestores das unidades de negócios e seus gerentes, fundamentado pela metodologia do Balanced Scorecard (BSC). A periodicidade de análise crítica, a partir de então, é mensal, com a participação da controladoria, da presidência e de representantes da diretoria. Nesse momento, é avaliado o desempenho da unidade através do mapa estratégico. Existe, ainda, uma prestação de contas quadrimestral, do gestor de negócio e mais um assistente direto, perante toda a diretoria corporativa, para verificar o desempenho em relação ao compromisso firmado para o ano. Em todos esses momentos, são apresentadas as justificativas e os planos de ação para assegurar os resultados ou corrigir distorções verificadas.

A partir da análise do PE do Grupo Paquetá e somadas as considerações dos Diretores e Gerentes Corporativos, percebe-se que o direcionamento estratégico da empresa está sedimentado em quatro focos distintos, conforme segue:

- manter e buscar novos mercados e clientes para a produção de calçados de exportação, com marca de terceiros, gerando volume para a estrutura física que a empresa dispõe. Esse é um negócio que a empresa domina há mais de 30 anos e, por ser a marca "Paquetá" reconhecida no varejo internacional como produtora de calçados, existe aí um importante mercado a ser explorado, principalmente, sem a intermediação de agentes de exportação. Para isso, a empresa vem estruturando e capacitando uma estrutura comercial direcionada a esse propósito;

- fortalecer a atuação da marca própria Dumond no mercado interno e na exportação de produtos com marca própria, a fim de atingir a sua visão de futuro para o ano de 2010. A Dumond obteve reconhecimento no Brasil e, nos últimos anos, como marca de atualidade (moda) e inovação (design), para um público seleto e que exige exclusividade. Isso tem permitido a discussão consistente sobre as possibilidades de expansão desse negócio;

- expandir o negócio varejista, buscando ampliar sua participação nos segmentos de varejo em que atua;

- buscar novos mercados e clientes para atuação do negócio de curtume, isto é, não atender exclusivamente à manufatura da Paquetá, especializar-se em produtos de maior valor agregado.

Os negócios de cartão crédito e empreendimentos imobiliários, por serem recentes, possuem como ação atual a auto-sustentação até o momento da nova revisão do planejamento estratégico. O negócio agropecuário tem como meta buscar novos projetos para serem desenvolvidos na sua área instalada. Esses projetos estão sendo formulados. 
Para que essas estratégias sejam alcançadas, pouco será necessário investir na estrutura física da empresa, uma vez que esta já está consolidada. Por outro lado, melhorar os processos das áreas de apoio, como recursos humanos, marketing e qualificar as pessoas da empresa serão tarefas essenciais para o "sucesso" de tais objetivos.

A Figura 2, apresentada a seguir, mostra como está integrado o sistema de gestão do Grupo Paquetá. A partir do planejamento estratégico, baseado no BSC, indicam-se os objetivos do Grupo, direcionando as perspectivas relacionadas às prioridades do contexto, que são: financeira, clientes, processos internos, pessoas e tecnologias. A partir dessas definições, mostra os processos a serem seguidos para o desenvolvimento de cada perspectiva, isto é, a perspectiva financeira é consolidada através do processo de controladoria; as perspectivas relacionadas aos clientes e aos processos internos são consolidadas através dos processos: comercial/desenvolvimento, planejamento, logística e produção. Já a perspectiva relacionada às pessoas e à tecnologia é consolidada por meio das ações de recursos humanos, informática, manutenção e sistemas produtivos. Ainda, indica as ferramentas que devem ser utilizadas para controlar os processos desenvolvidos nas perspectivas, tais como: contabilidade gerencial, business inteligent (BI) comercial - sistema de controladoria, ISO 9001, seis sigma, Controle Estatístico de Processos (CEP), sistema enxuto de produção focado em melhoria de processo e redução de tempo (LEAN), manutenção produtiva total (TPM), Grupos Participativos Paquetá (GPP), Fornecedores Qualidade Assegurada (FQA), Sistema de Informações Gerenciais Aplicadas (SIGA), subsistemas de recursos humanos, informática, processos e equipamentos. Com isso, geram as metas a serem alcançadas e estabelecem projetos para a sustentação de todo o sistema. 


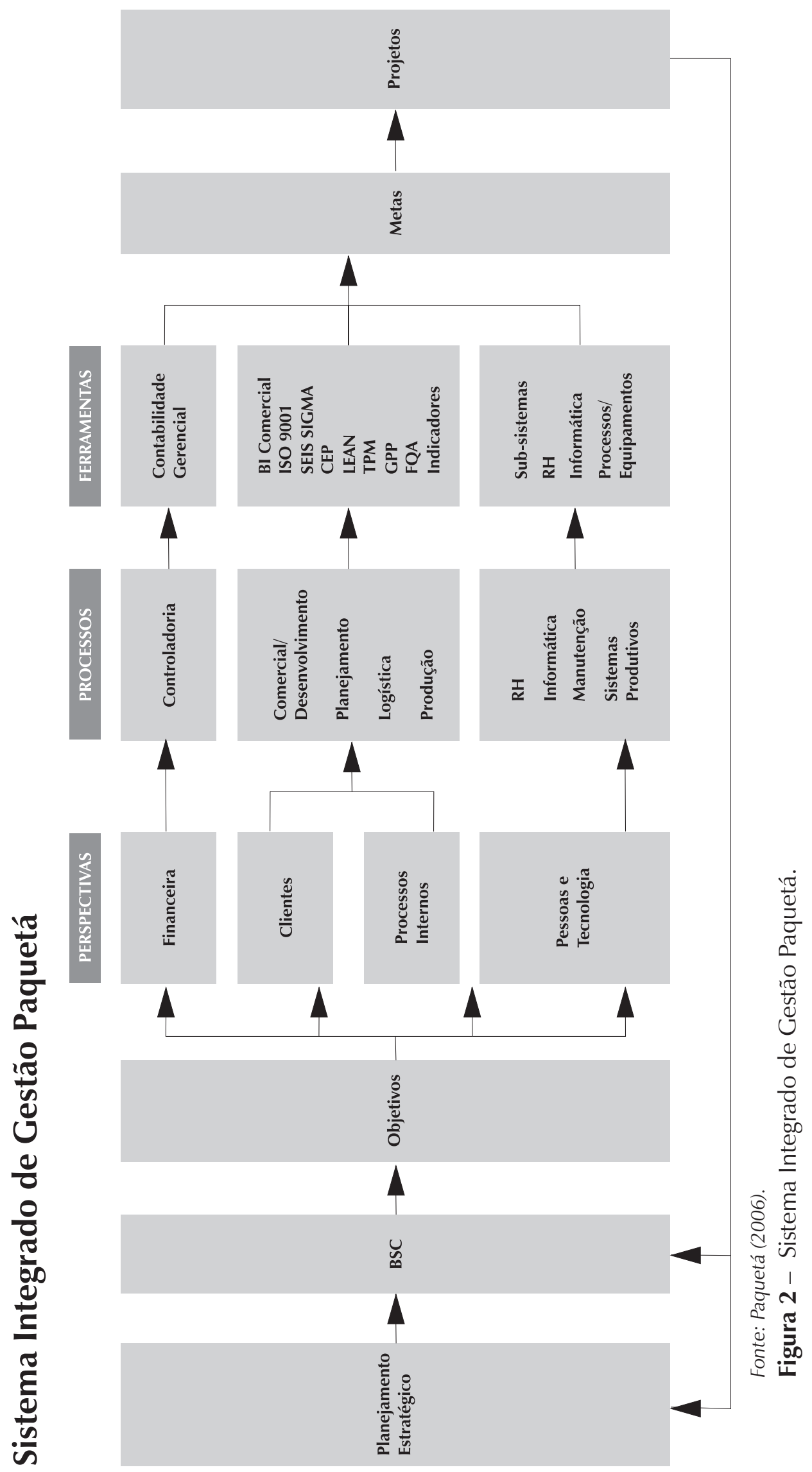

Rev. Adm. UFSM, Santa Maria, v. 1, n. 2, p. 241-262, mai./ago. 2008 
Percebe-se que o Grupo Paquetá formalizou suas estratégias organizacionais por meio do planejamento estratégico, assumindo um caráter deliberado pelo sistema integrado de gestão Paquetá. Em outras palavras, assume um padrão de ação que admite como pressuposto um comportamento pretendido, devidos às intenções precisas, estabelecidas previamente pela direção do Grupo e que são revistas anualmente e adaptadas conforme as interferências causadas pelo ambiente externo. Mas, de acordo com o dinamismo do mercado, são adotadas estratégias emergentes (MINTZBERG, 2001; MARIOTTO, 2003). Portanto, as estratégias deliberadas e emergentes, tomadas juntamente pelo Grupo Paquetá representam uma adaptação entre o ambiente dinâmico e o ambiente estável. Assim o Grupo vai se ajustando continuamente ao ambiente no qual está inserido.

Importante salientar que, antes de instituir o planejamento estratégico formalizado, o Grupo já adotava estratégias deliberadas e emergentes de modo informal. Mas a nova configuração num sistema integrado de gestão permite melhor visualização de onde se está e onde se pretende chegar para aumentar a rentabilidade.

\subsection{Posicionamento e vantagem competitiva da Paquetá}

O posicionamento competitivo dentro de um setor é que determina se uma empresa terá rentabilidade abaixo ou acima da média nesse setor e repercute na vantagem competitiva se obtiver taxas maiores de rentabilidade do que as empresas rivais. Para isso, é importante estarem bem definidos o posicionamento e o escopo da organização (FAIRBANKS e LINDSAY, 2000; HEXSEL e PAIVA, 2006; BESANKO, 2006).

Além da definição do posicionamento, é importante a escolha do escopo (PORTER, 1986), pois indica a decisão sobre a prioridade quanto a investimentos em produtos e mercados. Nesse sentido, detalha-se o escopo dos negócios de manufatura do Grupo Paquetá: exportação de marcas de terceiros, mix de marcas de exportação, calçados esportivos, Dumond e varejo, detalhados a seguir:

a) Escopo da exportação de marca de terceiros (segmento feminino): as atividades relacionadas ao escopo da exportação são conduzidas pelo departamento comercial da empresa, que tem como objetivo: "Manter contatos com os clientes criando vínculos comerciais com o objetivo de manter os volumes atuais de produção e buscar novos mercados, a fim de assegurar o preenchimento da carteira de pedidos"

b) Mix de marcas da exportação: Antonio Melani, Gianni Bini, Nordstron, Aerosoles, Kate Spade, Gap, Hugo Boss, Tori Burch, Bcbgmaxazria, ColeHaan, Jessica Simpson, Oscar de la Renta, Anne Klein, Signature, entre outras.

O mercado principal da exportação de marca de terceiros ainda está focado nos Estados Unidos, representado por um universo de 150.000.000 consumidoras das classes " $E$ " até " $\mathrm{A}$ ". A participação da empresa nesse mercado está configurada conforme a Tabela 1. 
Tabela 1 - Participação da Paquetá no mercado de exportação de marca de terceiros nos EUA

\begin{tabular}{c|c|c|c}
\hline Classe & $\begin{array}{c}\text { Representação do } \\
\text { Mercado Consumidor }\end{array}$ & $\begin{array}{c}\text { Participação da } \\
\text { Paquetá }\end{array}$ & $\begin{array}{c}\text { Faixa de preço de } \\
\text { venda na loja }\end{array}$ \\
\hline "AA" & $1 \%(1.500 .000)$ & $0 \%(0)$ & Acima de $\$ 350$ \\
\hline "A" & $5 \%(7.500 .000)$ & $5 \%(375.000)$ & De \$199 a $\$ 349$ \\
\hline "B" & $10 \%(15.000 .000)$ & $10 \%(1.500 .000)$ & De \$129 a \$199 \\
\hline "C" & $15 \%(22.500 .000)$ & $25 \%(5.625 .000)$ & De \$89 a \$129 \\
\hline “D" & $20 \%(30.000 .000)$ & $40 \%(12.000 .000)$ & De \$69 a \$89 \\
\hline "E" & $49 \%(73.500 .000)$ & $20 \%(14.700 .000)$ & Até \$69 \\
\hline
\end{tabular}

Fonte: Elaborado pelas autoras, com base em fontes do Grupo Paquetá.

É importante destacar que o negócio de manufatura de marca de terceiros, até o ano 2001, estava concentrado nas classes "D" e " $E$ "; a partir de então, estão buscando as classes " $C$ ", "B" e "A". A perspectiva da Paquetá é atender somente às classes "AA", "A" e "B" até o ano 2010. A estratégia, para isso, é a busca de marcas consagradas no mundo da moda internacional, como, por exemplo, Hugo Boss, Ralph Lauren e Oscar de la Renta, que já estão em produção. A presença de muitas das marcas citadas, no Brasil, concentram-se exclusivamente na Paquetá, por exemplo, J.Vincent, Tori Burch e Signature.

Em relação à exportação, pode-se destacar que há exemplos claros de escopos "restritos" e "amplos" ao mesmo tempo: restrito, porque ainda se concentra no mercado americano; amplo, devido à quantidade de marcas produzidas pela empresa e ao público (classes) a que se destinam.

c) Escopo do esportivo: o escopo para o mercado de calçados esportivos está associado a determinados esportes, conforme os seguintes exemplos:

- futebol: existem quatro categorias de produtos, uma para cada tipo de jogo - futebol de campo; futebol society, indoor e futsal;

- running: existem duas categorias de produtos: uma para prática profissional ou para corredores que procuram produtos de alta tecnologia; e outra para quem utiliza os produtos somente para o dia-a-dia e caminhadas leves;

- tennis: produtos específicos para a prática do esporte Tênis.

d) Escopo Dumond: Aa unidade de negócio representada pela marca Dumond tem a seguinte configuração:

- tipo de produto: calçados, bolsas e acessórios femininos;

- estratégia de venda/mercado: a venda é feita para clientes "multimarcas" de todo o Brasil e para mais de 50 países do mundo;

- lojas próprias: desde 2004, a Dumond atua com suas lojas próprias. Em 2007, eram mais de dez lojas;

- o próximo passo na condução da estratégia do negócio é a abertura de franquias da marca;

- público alvo: mulheres classe A e B. 
Da mesma forma, pode-se dizer que se trata de uma mistura de escopos "restritos" e "amplos": restrito, devido ao público que se destina; e amplo, devido à diversidade de clientes e mercados.

e) Escopo varejo: o escopo é definido conforme as suas bandeiras: Lojas Paquetá, Paquetá Esportes, Gaston, Walk Run e Esposende.

Portanto, apresenta um escopo amplo devido à diversidade de clientes e mercados e aos públicos que se destina.

Quanto à concorrência, no segmento feminino de exportação de marca de terceiros, destaca-se a China como o principal concorrente. Mas o diferencial da Paquetá em relação a China se refere à qualidade dos produtos, ao atendimento do cliente, à agilidade de entrega e à flexibilidade. Os concorrentes da Dumond no mercado interno são a Schutz e a Arezzo; no mercado externo, possuem vários concorrentes, e cada país tem os seus. Já os concorrentes da marca Diadora, encontram-se num nível intermediário entre a marca Nike e a marca Olympikus. No negócio de varejo, o principal concorrente é as Lojas Renner, mas o maior dos concorrentes é a informalidade, pois abriram, no mercado, várias "lojas" de sapatos em pavilhões, essas surgem a todo instante.

Na Tabela 2, aponta-se a concentração de empresas exportadoras brasileiras por faixa de embarque. A Paquetá concentra-se na faixa de mais de US\$50 milhões, ou seja, entre as seis primeiras empresas que representam $0,47 \%$ do setor calçadista brasileiro.

Tabela 2 - Concentração das empresas exportadoras de calçados em 2005

\begin{tabular}{l|c|c|c|c}
\hline \multicolumn{1}{c|}{ Faixa de Embarque } & N.o de Empresas & $\%$ & US\$ Milhões & $\%$ \\
\hline+ US\$ 50 milhões & 6 & 0,47 & 434 & 22,87 \\
\hline 25 a US\$ 50 milhões & 12 & 0,95 & 411 & 21,67 \\
\hline 10 a US\$ 25 milhões & 28 & 2,22 & 407 & 21,45 \\
\hline 5 a US\$ 10 milhões & 30 & 2,37 & 220 & 11,59 \\
\hline 1 a US\$ 5 milhões & 119 & 9,41 & 304 & 16,02 \\
\hline De 0,1 a US\$1 milhão & 301 & 23,81 & 106 & 5,56 \\
\hline Menos de US\$ 0,1 milhão & 768 & 60,76 & 16 & 0,85 \\
\hline Totais & 1.264 & 100,00 & 1.899 & 100,00 \\
\hline
\end{tabular}

Fonte: MDIC/SECEX, 2005.

Cada negócio do Grupo possui uma rentabilidade diferenciada, que varia conforme a situação do mercado. Mas, no final, o resultado, ou seja, a soma de todos os negócios corresponde com o valor projetado. Na Tabela 3, apresenta-se a evolução da participação dos negócios do Grupo no faturamento em percentagem. 
Tabela 3 - Evolução da participação dos negócios no faturamento do Grupo Paquetá em \%: 1945-2006

\begin{tabular}{c|c|c|c|c|c|c|c|c}
\hline Ano & $\begin{array}{c}\text { Exportação } \\
\text { Marca } \\
\text { Terceiros }\end{array}$ & $\begin{array}{c}\text { Mercado } \\
\text { Interno e } \\
\text { Dumond }\end{array}$ & Esportivo & Curtume & Agronegócio & Varejo & $\begin{array}{c}\text { Cartóes } \\
\text { Crédito }\end{array}$ & $\begin{array}{c}\text { Empreendi- } \\
\text { mentos } \\
\text { Imobiliários }\end{array}$ \\
\hline 1945 & - & $100 \%$ & - & - & - & - & - & - \\
\hline 1955 & - & $100 \%$ & - & - & - & - & - & - \\
\hline 1965 & - & $95,00 \%$ & - & - & - & $5,00 \%$ & - & - \\
\hline 1975 & $86,00 \%$ & $5,00 \%$ & - & - & $1,00 \%$ & $8,00 \%$ & - & - \\
\hline 1985 & $83,13 \%$ & $2,37 \%$ & - & - & $2,65 \%$ & $11,86 \%$ & - & - \\
\hline 1995 & $47,83 \%$ & $3,49 \% * *$ & - & - & $4,01 \%$ & $44,67 \%$ & - & - \\
\hline 2005 & $27,81 \%$ & $7,58 \%$ & $13,32 \%$ & $8,93 \%$ & $1,78 \%$ & $38,83 \%$ & $1,66 \%$ & $0,10 \%$ \\
\hline $2006 *$ & $23,63 \%$ & $12,26 \%$ & $12,99 \%$ & $8,71 \%$ & $1,79 \%$ & $38,64 \%$ & $1,79 \%$ & $0,19 \%$ \\
\hline
\end{tabular}

Fonte: Paquetá, 2006 - base de faturamento.

* de janeiro até setembro de 2006

** a Dumond iniciou as atividades em 1995, nos anos anteriores eram produzidas outras marcas para o mercado interno.

Com base na análise da Tabela 3, percebe-se que, mesmo com a evolução de novos negócios, a manufatura ainda representa aproximadamente $50 \%$ do faturamento do Grupo. Vale destacar o crescimento progressivo da marca própria Dumond no faturamento que, desde o seu início, em 1995, até setembro de 2006 teve um crescimento de 350\%.

Portanto, pode-se concluir que, no negócio de manufatura, a exportação da marca de terceiros vem, ao longo da trajetória do Grupo, diminuindo a participação no faturamento, mas esse espaço está sendo preenchido pela marca própria Dumond e pelo segmento esportivo. O negócio do curtume mantém-se dentro de um mesmo percentual de participação no faturamento.

No negócio agropecuário, vê-se que a maior participação no faturamento do Grupo foi na década de 1990, porque foi contratada uma empresa de consultoria para implementar um programa de melhoramento genético dos animais e, conseqüentemente, teve maior rentabilidade.

Também se observa que o varejo teve um grande crescimento no período de 1995, pois, em 1994, a empresa adquiriu a rede de lojas Gaston, duplicando o número de lojas. A partir de 1995, manteve uma média de aproximadamente $40 \%$ do faturamento do Grupo.

Já o negócio de cartões de crédito mantém-se instável desde o seu inicio. Contudo, há perspectivas de crescimento na participação no faturamento do Grupo, porque começou a administrar o cartão de crédito (Praticard) em outras empresas do setor calçadista, situadas no Vale do Sinos.

Quanto ao negócio de empreendimentos imobiliários, por ser recente, tem ainda uma participação pouca expressiva no faturamento do Grupo. Os loteamentos iniciaram somente em 2006. 


\subsection{Os níveis estratégicos da Paquetá: corporativo, de negócios e funcional}

Conforme foi destacado na fundamentação teórica, as estratégias deliberadas e emergentes podem ser classificadas em função do nível interno da estrutura organizacional, onde são tomadas as decisões. Essa classificação pontua: a estratégia corporativa (do grupo empresarial), de negócios (de uma unidade estratégica de negócios, empresa ou divisão) e funcional (PIRES, 1995).

O Grupo Paquetá pode ser enquadrado nessa classificação, pois, desde a sua nova configuração, a partir do planejamento estratégico e do sistema integrado de gestão, apresenta a estrutura demonstrada na Figura 3. Dessa forma, estabelece-se um plano de alocação de recursos e de trocas de experiências para vantagem competitiva. É importante destacar que cada negócio possui definido seu posicionamento e escopo competitivo, que é confirmado junto ao corpo diretivo. Além disso, a estruturação em UEN é descentralizada e cada negócio possui autonomia para atuar, desde que apresente os resultados projetados.

\section{ORGANOGRAMA DIRETIVO}

\section{Diretor Presidente}

Diretor
Administra-
tivo

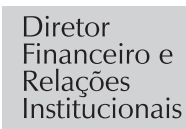

Diretor
Contábil
Fiscal

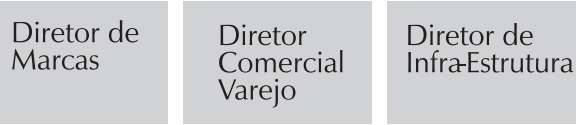

Diretor

Industrial

\section{ESTRUTURA DE NEGÓCIOS}

\section{Diretoria}
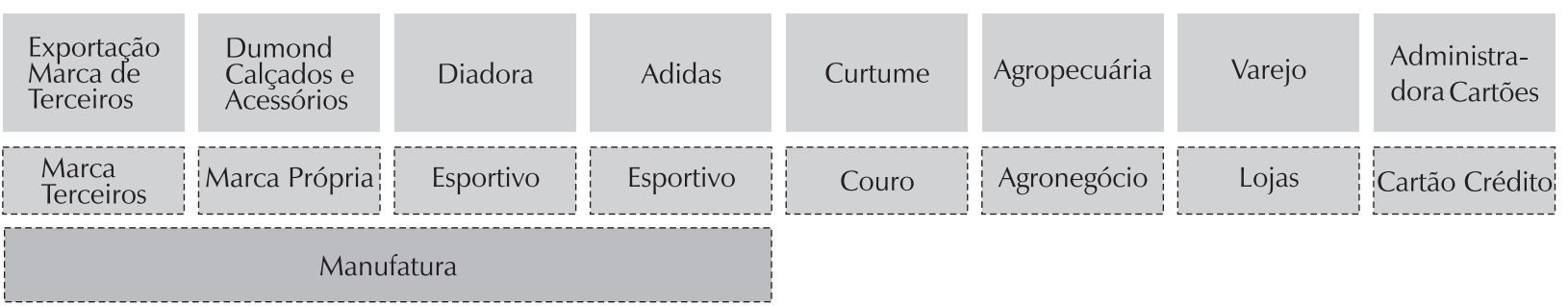

Fonte: Paquetá, 2006.

Figura 3 - Organograma diretivo e estrutura de negócios.

Segundo Lobato et al. (2005), esse tipo de estrutura organizacional facilita a coordenação estratégica, já que está distribuída por níveis e cada unidade é projetada com menor hierarquia e maior autonomia tornando o processo decisório mais participativo.

\section{Considerações finais}

Este artigo focalizou-se em uma dimensão histórica para compreender, a partir da trajetória da Paquetá, como a empresa foi desenvolvendo suas estratégias (1) capturando oportunidades de expansão em áreas correlatas de atuação com da diversificação de linhas de produção e de segmentos de mercado por faixa de renda, (2) mediante a integração vertical, e (3) expansão em outros negócios não correlatos, como empreendimentos imobiliários e administração de cartões de crédito. Vale destacar que a Paquetá soube aproveitar as 
oportunidades que surgiram, tais como: o ingresso no mercado externo no final da década de 1960, a aquisição da rede de lojas Gaston em 1994, e da rede Esposende em 2005.

Pode-se constatar que o negócio de manufatura de exportação de marca de terceiros e da marca própria possuem semelhanças no processo produtivo, pois ambos estão direcionados para o segmento feminino. Quanto às diferenças, na exportação de marca de terceiros, o produto vem definido pelo cliente e, na Dumond, o processo é o inverso, ou seja, é criado e oferecido aos clientes.

Por meio deste estudo, comprova-se que é possível não só produzir simultaneamente marcas de terceiros, principalmente se a empresa já for reconhecida mundialmente, como é o caso da Paquetá, mas também ter uma marca própria, apesar do tempo demandado para sua consolidação em nível mundial e considerada a sustentabilidade da empresa.

Inspirado no estudo de caso da Paquetá, sugere-se que, para que o setor calçadista brasileiro aumente sua competitividade, deverá buscar um diferencial que ainda os países asiáticos não possuem, tais como: produzir produtos mais sofisticados, ter maior rapidez na entrega, buscar maior união das empresas entre componentes, curtumes e calçados.

A resposta da Paquetá à nova situação competitiva no mercado internacional tem sido atuar com marca própria e comercializar diretamente produtos de marca de terceiros, sem o intermédio do agente. O negócio de manufatura da marca de terceiros está buscando esse mercado de alto valor agregado como alternativa para não competir com a China.

Quanto às perspectivas em termos de novos desafios e necessidades, considerando-se o contexto competitivo, o Grupo Paquetá identifica alguns focos: (a) desenvolver e consolidar a competência de relacionamento com clientes para buscar marcas " $A A^{\prime}$ e " $\mathrm{A}$ " no negócio de exportação de marca de terceiros, pois está se estruturando para atender pedidos diferenciados e de pequenos volumes através de grupos de trabalho; (b) adquirir marcas consolidadas no mercado no intuito de obter maior participação, podendo terceirizar sua produção em outros países ou produzir em sua planta industrial; (c) ampliar o varejo Paquetá e o varejo Dumond, objetivando fortalecer-se e manter-se como principal rede de varejo do País, além de internacionalizar o varejo da marca Dumond; (d) estruturar a remuneração variável por desempenho das unidades de negócio para estimular a capacidade de entrega dos gestores de cada unidade; (e) buscar maior inserção internacional da marca Dumond, sendo então possível consolidar a visão estabelecida pela Paquetá "ter uma marca com posicionamento no mundo até 2010"; (f) alcançar maior integração e comprometimento entre curtumes, componentes (fornecedores) e calçados para agregar maior valor ao produto.

Este estudo buscou trazer algumas reflexões acerca do setor calçadista, ilustrando a experiência da Paquetá ao adotar uma estratégia de diversificação que trouxe benefícios e estabilidade durante os períodos de crise que o setor enfrentou e enfrenta. Além disso, destacase que, por meio da estratégia de diversificação, é possível ingressar em novos mercados que, geralmente, trazem novas perspectivas para empresa. Por fim, este estudo mostra que, por meio do resgate da trajetória de uma organização, podem ser encontradas as causas e os motivos que levaram a Paquetá a ser um caso de "sucesso" embora as crises enfrentadas pelo setor calçadista, em que um grande número de empresas não sobreviveu às novas demandas e à concorrência acirrada imposta pelo mercado. 


\section{Referências}

ANDREWS, K. O conceito de estratégia empresarial. In: MINTZBERG, H.; QUINN, J. B. O processo da estratégia. 3. ed. Porto Alegre: Bookman, 2001. p. 58-64.

ANSOFF, H. Igor. A nova estratégia empresarial. São Paulo: Atlas, 1990.

BESANKO, D. et al. A economia da estratégia. 3. ed. Porto Alegre: Bookman, 2006.

CHANDLER, JR. A. Strategy and structure. Cambridge: MIT Press, 1962.

CHURCHILL, JR. G.A. Marketing research: methodological foundations. Chicago: The Dryden, 1987.

DOSI, G.; TEECE, D.; WINTER, S. Toward a theory of corporate coherence: preliminary remarks. In: DOSI, G. et al. Technology and enterprise in a historical perspective. Oxford: Claredon, 1992.

FAIRBANKS, M.; LINDSAY, S. Arando o mar: fortalecendo as fontes ocultas do crescimento em países em desenvolvimento. Rio de Janeiro: Quality Mark, 2000.

FLICK, Uwe. Uma introdução à pesquisa qualitativa. Porto Alegre: Bookman, 2004.

GALBRAITH, J. R. Planejamento estratégico e de organização. In: MINTZBERG, H.; GEORGE, K. D.; JOLL, C. (Orgs.). Organização industrial: concorrência, crescimento e mudança estrutural. Rio de Janeiro: Zahar, 1983.

HEXSEL, A.; HENKIN, H. Os conceitos de eficácia operacional e estratégia propostos por Porter: fundamentos econômicos e análise crítica. Salvador: ENANPAD, 2002.

HEXSEL, A. E.; PAIVA, E. L. A construção de estratégias de sucesso por pequenas $\mathrm{e}$ médias empresas que atuam em setores fragmentados: um estudo de caso. Salvador: ENANPAD, 2006.
LEE, T. W. Using qualitative methods in organizational research. California: Sage, 1998.

LOBATO, D. et al. Estratégia de empresas. 6. ed. São Paulo: Fundação Getúlio Vargas, 2005.

MARIOTTO, F. L. Mobilizando estratégias emergentes. RAE - Revista Administração Empresas, São Paulo, v. 43, n. 2, p. 78-93, abr./ maio/jun. 2003.

MARSHALL, C.; ROSSMAN, G. B. Designing qualitative research. California: Sage, 1999.

MDIC/SECEX. Ministério do desenvolvimento, indústria e comércio exterior/secretária de comércio exterior. Disponível em: <www. desenvolvimento.gov.br $>$. Acessos em: 9 set. 2004; 19 jun. 2005; 2 ago. 2006.

MINTZBERG, H. A organização diversificada. In: MINTZBERG, H.; QUINN, J. B. O processo da estratégia. 3. ed. Porto Alegre: Bookman, 2001. p. 316-326.

PAIVA, E. L.; CARVALHO, J. M.; FENSTERSEIFER, J. E. Estratégia de produção e operações. Porto Alegre: Bookman, 2004.

PENROSE, E.T. The theory of the growth of the firm. Oxford: Brasil Blackwell, 1959.

PIRES, S. Gestão estratégica da produção. Piracicaba: Unimep, 1995.

PORTER, M. Estratégia competitiva: técnicas para análise de indústrias e da concorrência. Rio de Janeiro: Campus, 1986.

WHITTINGTON, R. National innovation and transnational variation. In: CLEGG, S.; CASTER, C.; KORNBERGER, M. A máquina estratégica: fundamentos epistemológicos e desenvolvimentos em curso. RAE - Revista de Administração de Empresas, São Paulo, v. 44, n. 4, out./dez., 2004 b. 